Explosive bubbles in house prices? Evidence from the OECD countries

Tom Engsted, Simon J. Hviid and Thomas Q. Pedersen CREATES Research Paper 2015-1 


\title{
Explosive bubbles in house prices? Evidence from the OECD countries*
}

\author{
Tom Engsted $†$ Simon J. Hviid $\ddagger$ Thomas Q. Pedersen ${ }^{\S}$
}

January 2015

\begin{abstract}
We conduct an econometric analysis of bubbles in housing markets in the OECD area, using quarterly OECD data for 18 countries from 1970 to 2013. We pay special attention to the explosive nature of bubbles and use econometric methods that explicitly allow for explosiveness. First, we apply the univariate right-tailed unit root test procedure of Phillips et al. (2012) on the individual countries price-rent ratio. Next, we use Engsted and Nielsen's (2012) co-explosive VAR framework to test for bubbles. We find evidence of explosiveness in many housing markets, thus supporting the bubble hypothesis. However, we also find interesting differences in the conclusions across the two test procedures. We attribute these differences to how the two test procedures control for cointegration between house prices and rent.
\end{abstract}

JEL Classification: C22, C32, G12

Keywords: Co-explosive VAR model, right-tailed unit root tests, date-stamping bubble periods, price-to-rent ratio

${ }^{*}$ The authors acknowledge support from The Danish Council of Independent Research (DFF - 4003-00022) and CREATES - Center for Research in Econometric Analysis of Time Series (DNRF78), funded by the Danish National Research Foundation. We thank Jérôme Brezillon for providing us with the OECD data along with Bent Nielsen and participants at the 14th OxMetrics User Conference, the Danish Academic Economists in North America Meeting 2014, and the 1st Conference on Recent Developments in Financial Econometrics and Applications for useful comments.

${ }^{\dagger}$ Corresponding author. CREATES, Department of Economics and Business, Aarhus University, Fuglesangs Allé 4, DK-8210 Aarhus V, Denmark. E-mail: tengsted@econ.au.dk. Phone: +45 87165572.

${ }^{\ddagger}$ CREATES, Department of Economics and Business, Aarhus University, Fuglesangs Allé 4, DK-8210 Aarhus V, Denmark. E-mail: shviid@econ.au.dk.

${ }^{\S}$ CREATES, Department of Economics and Business, Aarhus University, Fuglesangs Allé 4, DK-8210 Aarhus V, Denmark. E-mail: tqpedersen@econ.au.dk. 


\section{Introduction}

Many countries have experienced dramatic movements in house prices over the past 15-20 years, with large increases during the 1990s and first half of the 2000s followed by price drops since 2006-2007. This pattern is also visible in the ratio of prices to rents and has been especially pronounced in countries such as Spain, Ireland, Denmark, Sweden, the Netherlands, the UK, and the US. Understanding these developments is important, not least because the recent international financial crisis to a large extent originated from the housing markets, e.g. the subprime mortgages in the US and the overinvestment in housing in many European countries.

In general, changes in house prices must be due to one of two causes (or a combination of them), either changing 'fundamentals' or speculative bubbles. In the literature, rents are usually considered an important part of fundamentals for house prices, see e.g. Hamilton and Schwab (1985), Meese and Wallace (1994), Himmelberg et al. (2005), Gallin (2008), Brunnermeier and Julliard (2008), Campbell et al. (2009), Plazzi et al. (2010), Cochrane (2011), Ghysels et al. (2013), Engsted and Pedersen (2013, 2014), and Gelain and Lansing (2014). For the owner of a house who also lives in the house, rents can be seen as a proxy for the unobservable housing service flow and thus are the equivalent to the dividends that an owner of a stock obtains in the equity market.

However, the recent boom-bust developments in housing markets have generated a heated discussion of whether speculative bubbles could be a major factor in house price movements in addition to changing fundamentals. During the boom period several observers, most notably Shiller (2005), raised the possibility that a bubble was driving US house prices, while others, e.g. Himmelberg et al. (2005), McCarthy and Peach (2004), and Krainer and Wei (2005), argued that the US housing market was not inflated by a bubble.

After the end of the boom period a few studies have investigated the bubble hypothesis for the US housing market using formal econometric tests. Phillips and Yu (2011) basically use the econometric methods from Phillips et al. (2011), which rely on forward recursive regressions coupled with right-tailed unit root tests, to document explosive behavior in US house prices. Kivedal (2013) uses the co-explosive vector-autoregressive (VAR) methodology from Engsted and Nielsen (2012), and he also finds US house prices to be explosive. Thus, both these recent studies find evidence in support of the bubble hypothesis for the US.

To our knowledge, however, there has not been any systematic econometric analysis of explosiveness in house prices outside the US. In this paper we fill this gap in the literature. We conduct a thorough econometric analysis of bubbles in housing markets in the OECD area, using quarterly OECD data for 18 countries from 1970 to 2013 . We pay special attention to the

explosive nature of bubbles and use econometric methods that explicitly allow for explosiveness. First, we apply the univariate right-tailed unit root test procedure of Phillips et al. (2012), which 
is a generalization of the test procedure of Phillips et al. (2011), on the individual countries price-rent ratio. Next, we use Engsted and Nielsen's (2012) co-explosive VAR framework to test for bubbles while at the same time allowing prices to be cointegrated with fundamentals and estimating the cointegrating relationship.

The appealing feature of the co-explosive VAR framework of Engsted and Nielsen (2012) is that it allows prices to contain both an explosive component - coming from the bubble - and an $I(1)$ component coming from the non-stationary part of fundamentals, i.e. prices and fundamentals may 'cointegrate' despite the explosive root in prices. This is an important feature of traditional bubble models that is often neglected in empirical bubble studies although emphasized by Diba and Grossman (1988a) and Engsted (2006). The drawback of the coexplosive VAR methodology is that it assumes that the bubble period can be identified á priori; in principle the method does not allow for bursting or partially bursting bubbles during the sample period. Thus, the sample period needs to end before or at the peak of the bubble.

By contrast, the univariate right-tailed unit root test procedure of Phillips et al. (2012) is explicitly designed to capture bursting bubbles and to date-stamp the beginning and end of the bubble. Thus, this procedure can handle a sample period that contains both bubble and non-bubble sub-periods. The main drawback of the procedure is that it does not allow for both an explosive root and a unit root. The null hypothesis underlying the test is that the relevant time series is an $I(1)$ process, while it is explosive under the alternative. Applying the test on the price-rent ratio and rejecting the null hypothesis it is thus implicitly assumed that prices and rent cointegrate, which need not be the case. The co-explosive VAR framework does allow for both an explosive root and a unit root, and hence the two test procedures applied in this paper can potentially result in different conclusions regarding the presence of bubbles.

The main results of our analysis are as follows. First, using the univariate right-tailed unit root test procedure on the price-rent ratio we find evidence of bubbles in 16 of the 18 OECD countries' housing markets. Only in Germany and Italy do we not detect a bubble during the sample period from 1970 to 2013. Second, there appears to be a large degree of housing bubble synchronicity across the OECD countries. Most countries experience bubbles in their housing markets in the early 2000s. The exceptions are Japan, Switzerland, and Finland, who in contrast experienced bubbles around 1990. Third, using the co-explosive VAR framework we obtain results that for four countries (Ireland, Norway, Sweden, and the US) are consistent with the univariate analysis in that we find evidence of both explosiveness and cointegration between prices and rents. For another four countries (Australia, Denmark, Finland, and France) we still find evidence of bubbles but also of no common $I(1)$ trend in the relation between prices and rents. For the remaining 10 countries the co-explosive VAR analysis does not indicate the presence of an explosive housing bubble.

The rest of the paper is organized as follows. In the next section the bubble model is described. Section 3 describes the econometric methodologies. That section also contains a 
comparison of our approach with earlier bubble tests. In section 4 we present the empirical results using data from the OECD countries. Section 5 concludes.

\section{The bubble model}

We start by considering the standard model for asset price determination that is often used in house price studies. Let $P_{t}$ denote the house price and $X_{t}$ the service flow, which we proxy by housing rents, both at time $t$. Given a constant and positive expected one period housing return, $R>0,{ }^{1} P_{t}$ is given as

$$
P_{t}=\frac{1}{1+R} E_{t}\left(P_{t+1}+X_{t+1}\right)
$$

where the expectation operator, $E_{t}$, is conditioned on information at time $t$. From (1) the general solution for $P_{t}$ is

$$
P_{t}=\sum_{i=1}^{\infty}\left(\frac{1}{1+R}\right)^{i} E_{t} X_{t+i}+B_{t},
$$

where

$$
B_{t}=\frac{1}{1+R} E_{t} B_{t+1}
$$

$B_{t}$ is the bubble component that reflects self-fulfilling expectations: the bubble is only present at time $t$ if it is expected to be present at time $t+1$. From (3) it follows that $B_{t+1}=(1+R) B_{t}+\xi_{t+1}$, where $\xi_{t+1}$ is a rational forecast error such that $E_{t} \xi_{t+1}=0$. Note that the restriction $R>0$ implies that any rational bubble must have an explosive root in its autoregressive representation.

The bubble component can be eliminated by imposing a transversality condition $\lim _{T \rightarrow \infty}(1+$ $R)^{-T} E_{t} P_{t+T}=0$ when solving (1) recursively forward for $P_{t}$. In that case house prices are determined only by the present value of expected future rents, i.e. the first term on the right-hand side of (2). In this paper, however, we do not impose the no-bubble transversality condition.

We can, following Campbell and Shiller (1987), define the 'spread' as $S_{t} \equiv P_{t}-\frac{1}{R} X_{t}$ and rewrite (2) into the following equation

$$
S_{t}=\frac{1+R}{R} \sum_{i=1}^{\infty}\left(\frac{1}{1+R}\right)^{i} E_{t} \Delta_{1} X_{t+i}+B_{t}
$$

where $\Delta_{1} X_{t+i} \equiv X_{t+i}-X_{t+i-1}$ is the first-difference of $X_{t+i}$. Equation (4) shows that if there is no bubble $\left(B_{t}=0\right)$ and rents have a unit root, i.e. $X_{t} \sim I(1)$, then prices, $P_{t}$, will share the unit root with $X_{t}$ such that the spread $S_{t}$ is stationary, $I(0)$, i.e. $P_{t}$ and $X_{t}$ cointegrate with cointegrating vector $\left(1,-\frac{1}{R}\right)$.

\footnotetext{
${ }^{1}$ In most of the bubble literature expected returns are assumed to be constant. In section 3.3 we briefly discuss this assumption.
} 
If there is a bubble, $B_{t}>0$, then $P_{t}$ and $X_{t}$ still share a stochastic $I(1)$ trend such that $S_{t}$ does not contain a unit root. However, in that case $P_{t}$ will also contain the explosive root coming from the bubble. Thus, $P_{t}$ and $X_{t}$ are still 'cointegrated' in the sense that the linear combination given by $S_{t}$ has no $I(1)$ component but it is not stationary since it contains the explosive bubble component.

Our VAR analysis in Section 4 will be based on the parameterization in (4). Following Craine (1993), another useful reparameterization of (2) is to divide both sides by $X_{t}$ to give an expression for the price-rent ratio in terms of expected future compounded growth rates in rents and the bubble-rent ratio:

$$
\frac{P_{t}}{X_{t}}=\sum_{i=1}^{\infty}\left(\frac{1}{1+R}\right)^{i} \frac{E_{t} X_{t+i}}{X_{t}}+\frac{B_{t}}{X_{t}}
$$

If $B_{t}=0$ and $P_{t}$ and $X_{t}$ have a common stochastic $I(1)$ trend, the price-rent ratio $P_{t} / X_{t}$ will be stationary (cf. Craine, 1993). However, if there is a bubble, $B_{t}>0$, the price-rent ratio will be explosive. If there is a bubble and prices and rents do not have a common $I(1)$ trend, i.e. they do not 'cointegrate', $P_{t} / X_{t}$ may contain both a unit root and an explosive root. A unit root in $P_{t}$ that is unrelated to $X_{t}$ may come from other parts of fundamentals besides rents, e.g. household disposable income. Part of our analysis in Section 4 will be based on the expression in (5).

In theory the above model setup does not imply riskless arbitrage opportunities despite the bubble. Since the bubble evolves according to (3), it is consistent with the no-arbitrage relation (1), cf. Diba and Grossman (1988b). Thus, despite the presence of a bubble, the model describes an informationally efficient market with positive and constant expected returns. It is well-documented that housing markets are not informationally efficient, see e.g. Case and Shiller (1989), so in our empirical analysis we will not focus on the strict efficient markets implications of the model. Instead, we will focus on the cointegration and explosive properties that follow from (4) and (5).

\section{The econometric methodology}

\subsection{Right-tailed unit root tests and date-stamping}

As noted in Section 2 a key issue in identifying rational bubbles is whether we can detect explosive behavior in the spread $P_{t}-\frac{1}{R} X_{t}$ and the price-rent ratio $P_{t} / X_{t}$. With the aim of identifying potential rational bubbles in the stock market, Diba and Grossman (1988a) suggest the use of right-tailed unit root tests to detect explosiveness, i.e. instead of testing the null of a unit root against stationarity one should test against the explosive alternative. However, using 
a simulation study Evans (1991) shows that this test procedure has very low power in detecting periodically collapsing bubbles.

Motivated by the idea of Diba and Grossman (1988a) and the findings of Evans (1991), Phillips et al. (2011) propose to conduct a series of right-tailed unit root tests based on an expanding window (with a fixed start date) of data with the largest of these test statistics being the relevant test statistic for explosiveness. They name this test the supremum augmented Dickey-Fuller (SADF) test and show that it has much better power properties in the presence of periodically collapsing bubbles than a unit root test based on the entire sample as proposed by Diba and Grossman (1988a). Phillips et al. (2012) generalize the test procedure by allowing both the start and end date to vary and find that this approach has even higher power than the SADF test in detecting periodically collapsing bubbles. An important feature of both the SADF and generalized SADF (GSADF) test procedure is that it enables us to date-stamp periods with explosive behavior. We will make use of GSADF and the date-stamping procedure proposed by Phillips et al. (2012) to test for explosiveness in the price-rent ratio and to pinpoint periods with explosive behavior.

\subsubsection{The GSADF test}

The null hypothesis in the GSADF test procedure is that the relevant time series, $y_{t}$, follows a random walk process with an asymptotically negligible drift

$$
y_{t}=d T^{-\eta}+\theta y_{t-1}+\varepsilon_{t}, \quad \varepsilon_{t} \stackrel{i i d}{\sim} N\left(0, \sigma^{2}\right), \quad \theta=1
$$

where $d$ is a constant and $\eta>1 / 2$ is a coefficient that controls the magnitude of the drift as the sample size, $T$, goes to infinity. ${ }^{2}$ Before explaining the GSADF test procedure it is useful to introduce some notation. Let $r_{1}$ and $r_{2}$ denote fractions of the total sample with $r_{2}=r_{1}+r_{w}$, where $r_{w}>0$ is the fractional window size used in the auxiliary regressions underlying the test procedure. This implies that in the regressions we will use $T_{w}=\left\lfloor T r_{w}\right\rfloor$ observations, where $\lfloor\cdot\rfloor$ denotes the integer part of the argument. Also, let $r_{0}$ denote the smallest fractional window size used.

Based on the data-generating process under the null hypothesis (6), Phillips et al. (2012) use the following auxiliary regression when performing the unit root tests

$$
y_{t}=\mu_{r_{1}, r_{2}}+\delta_{r_{1}, r_{2}} y_{t-1}+\sum_{j=1}^{k} \phi_{j, r_{1}, r_{2}} \Delta y_{t-j}+\varepsilon_{t}, \quad \varepsilon_{t} \stackrel{i i d}{\sim} N\left(0, \sigma_{r_{1}, r_{2}}^{2}\right),
$$

where the subscript $r_{1}, r_{2}$ is used to illustrate that (7) is estimated using a sample that begins

\footnotetext{
${ }^{2}$ Phillips et al. (2012) set $d$ and $\eta$ to 1 , while Phillips et al. (2011) effectively set $\eta \rightarrow \infty$, corresponding to a null hypothesis of a random walk without drift.
} 
with observation $\left\lfloor T r_{1}\right\rfloor$ and ends with $\left\lfloor T r_{2}\right\rfloor$. Based on the auxiliary regression (7) we can test the null hypothesis of a unit root $\left(\delta_{r_{1}, r_{2}}=1\right)$ against the explosive alternative $\left(\delta_{r_{1}, r_{2}}>1\right)$. We denote the corresponding $\mathrm{ADF}$ test statistic by $A D F_{r_{1}}^{r_{2}}$.

The GSADF test statistic, which is a function of $r_{0}$, is defined as

$$
G S A D F\left(r_{0}\right)=\sup _{\substack{r_{2} \in\left[r_{0}, 1\right] \\ r_{1} \in\left[0, r_{2}-r_{0}\right]}}\left\{A D F_{r_{1}}^{r_{2}}\right\}
$$

The ending point of the sample sequence varies from $\left\lfloor T r_{0}\right\rfloor$ to $T$, while the starting point varies from the first observation to $\left\lfloor T\left(r_{2}-r_{0}\right)\right\rfloor$. The GSADF test is the supremum of the corresponding sequence of ADF test statistics. The SADF test statistic is a special case of the GSADF test where $r_{1}=0$. GSADF and SADF both have nonstandard limiting distributions, so critical values are obtained by means of simulation.

\subsubsection{Date-stamping}

Phillips et al. (2012) propose a backwards supremum ADF (BSADF) test procedure to pinpoint periods with explosive behavior. The BSADF test statistic, which is also a function of $r_{0}$, is defined as

$$
B S A D F_{r_{2}}\left(r_{0}\right)=\sup _{r_{1} \in\left[0, r_{2}-r_{0}\right]}\left\{B A D F_{r_{1}}^{r_{2}}\right\},
$$

where $B A D F_{r_{1}}^{r_{2}}$ denotes the ADF test statistic using a sample with starting point $\left\lfloor T r_{1}\right\rfloor$ and ending point $\left\lfloor T r_{2}\right\rfloor$. For each value of $r_{2}$ we thus get a sequence of BADF statistics, and the BSADF test statistic is the supremum of these. Based on the series of BSADF test statistics, Phillips et al. (2012) define the (fractional) origination and termination points of explosive behavior $\left(\widehat{r}_{e}\right.$ and $\left.\widehat{r}_{f}\right)$ as

$$
\begin{aligned}
& \widehat{r}_{e}=\inf _{r_{2} \in\left[r_{0}, 1\right]}\left\{r_{2}: B S A D F_{r_{2}}\left(r_{0}\right)>c v_{r_{2}}^{\alpha_{T}}\right\}, \\
& \widehat{r}_{f}=\inf _{r_{2} \in\left[\widehat{r}_{e}, 1\right]}\left\{r_{2}: B S A D F_{r_{2}}\left(r_{0}\right)<c v_{r_{2}}^{\alpha_{T}}\right\},
\end{aligned}
$$

where $c v_{r_{2}}^{\alpha_{T}}$ denotes the $100\left(1-\alpha_{T}\right) \%$ critical value of the SADF test statistic based on $\left\lfloor T r_{2}\right\rfloor$ observations. This identification scheme implies that the origination date of the bubble $\left\lfloor T \widehat{r}_{e}\right\rfloor$ is the first chronological observation where the BSADF test statistic exceeds the critical value, and correspondingly the termination date $\left\lfloor T \widehat{r}_{f}\right\rfloor$ is the first chronological observation after $\left\lfloor T \widehat{r}_{e}\right\rfloor$ where the BSADF test statistic falls below the critical value.

As mentioned in Section 2 a rational bubble, $B_{t}$, reflects self-fulfilling expectations meaning that the bubble is only present at time $t$ if it is expected to be present at time $t+1$. In addition, given rationality it must hold that $E_{t} \xi_{t+1}=0$ in $B_{t+1}=(1+R) B_{t}+\xi_{t+1}$. As a 
consequence, a rational bubble cannot burst and reappear but must have been present in the asset from the first time it was traded, cf. Diba and Grossman (1988b). This property appears to conflict with the idea of date-stamping bubble periods. However, rational bubbles can be periodically collapsing (see e.g. Evans, 1991) which implies that bubbles can burst partially and then begin to build up again. If the bubble component is small compared to fundamentals it will be hard to detect using econometric techniques meaning that the bubble has to be of a certain size before one can identify it. Date-stamping the presence of rational bubbles can thus be understood as identifying periods, where the bubble component has a significant size compared to fundamentals.

\subsection{The co-explosive VAR methodology}

The bubble testing procedure proposed by Engsted and Nielsen (2012) builds on the co-explosive framework developed in Nielsen (2010). Consider the vector $V_{t}=\left(P_{t}, X_{t}\right)^{\prime}$ and assume that it follows the $k^{\prime}$ 'th order vector autoregression (VAR)

$$
M: \quad V_{t}=\mu_{v}+\sum_{j=1}^{k} A_{j} V_{t-j}+\epsilon_{t}
$$

where $A_{j} \in \mathbb{R}^{2 \times 2}$ are the VAR parameter matrices, $\mu_{v} \in \mathbb{R}^{2}$ is the vector of deterministic terms, and $\epsilon_{t}$ is the vector of error terms. In accordance with Engsted and Nielsen (2012) we call this model $M$. If the characteristic polynomial for the autoregressive structure of (8) has an explosive root, $\rho>1$, the VAR model can be reparameterized in vector error correction (VECM) form as

$$
\Delta_{1} \Delta_{\rho} V_{t}=\mu_{v}+\Pi_{1} \Delta_{\rho} V_{t-1}+\Pi_{\rho} \Delta_{1} V_{t-1}+\sum_{j=1}^{k-2} \Phi_{j} \Delta_{1} \Delta_{\rho} V_{t-j}+\epsilon_{t}
$$

where $\Delta_{\rho}=(1-\rho L), L$ is the lag-operator, and $\Pi_{1}, \Pi_{\rho}, \Phi_{j} \in \mathbb{R}^{2 \times 2}$. Note that here $V_{t}$ is assumed to have a unit root in addition to the explosive root.

The VECM representation is linked to the VAR representation through the standard error correction form that follows from Granger's Representation Theorem,

$$
\Delta_{1} V_{t}=\mu_{v}+\Pi V_{t-1}+\sum_{j=1}^{k-1} \Gamma_{j} \Delta_{1} V_{t-j}+\epsilon_{t}
$$

and the following set of identities

$$
\Pi_{1}=\frac{\Pi}{1-\rho}, \quad \Pi_{\rho}=-\rho\left(I_{p}+\Pi_{1}+\sum_{j=1}^{k-1} \rho^{-j} \sum_{l=j+1}^{k} A_{l}\right), \quad \Phi_{j}=-\sum_{l=j+1}^{k-1} \rho^{j-l} \sum_{i=l+1}^{k} A_{i},
$$


where $\Pi, \Gamma_{j} \in \mathbb{R}^{2 \times 2}$.

In addition to the explosive root, $V_{t}$ has either one or two unit roots. If there is one unit root it implies that $P_{t}$ and $X_{t}$ have a common stochastic $I(1)$ trend, i.e. they are 'cointegrated'. If $P_{t}$ and $X_{t}$ are not cointegrated, there are two independent unit roots in the system. In the former case we have the following reduced rank restrictions $\Pi_{1}=\alpha_{1} \beta_{1}^{\prime}$ and $\Pi_{\rho}=\alpha_{\rho} \beta_{\rho}^{\prime}$, where $\alpha_{1}, \beta_{1}, \alpha_{\rho}, \beta_{\rho} \in \mathbb{R}^{2}$. Here $\beta_{1}$ has the common interpretation of a cointegrating relation of $V_{t}$, equivalent to the one identified by the spread, $S_{t}=P_{t}-\frac{1}{R} X_{t}$, in Section 2 . Therefore we have the model implied restriction $\beta_{1}=(1,-1 / R)^{\prime}$. Furthermore, $\beta_{\rho}$ is interpreted as a co-explosive vector that captures the common explosive component in $P_{t}$ and $X_{t}$. The case that we will be particularly interested in is when rents are non-explosive but prices are explosive due to a bubble. This case implies the following restriction on the co-explosive vector: $\beta_{\rho}=(0,1)^{\prime}$.

We now explain in more detail these restrictions and how to test them.

\subsubsection{The cointegration restriction}

The starting point in the estimation procedure is to estimate the unrestricted model $M$, equation (8). Next we compute the characteristic roots from the characteristic polynomial and if the largest root is larger than unity, $\hat{\rho}>1$, this serves as preliminary evidence of explosiveness. If the largest root is equal to or less than one, the system is just a standard $I(1)$ or stationary system. Hereafter, we apply the sequential cointegrating rank test of Johansen (1995). This corresponds to the null hypothesis

$$
H_{1}: \quad\left(\Pi_{1}, \mu_{v}\right)=\alpha_{1}\left(\beta_{1}^{\prime}, \zeta_{1}\right), \quad \Pi_{\rho}=\alpha_{\rho} \beta_{\rho}^{\prime}
$$

where $\zeta_{1} \in \mathbb{R}$ is a constant that is restricted to the cointegrating space. The null hypothesis implies a cointegrating relation between $P_{t}$ and $X_{t}$. The Johansen rank test is valid even in the presence of an explosive root, cf. Nielsen (2010). For $\hat{\rho}>1$, if we use $M_{1}$ to denote $M$ when restricted by $H_{1}$, then

$$
M_{1}: \quad \Delta_{1} \Delta_{\rho} V_{t}=\mu_{v}+\alpha_{1} \beta_{1}^{\prime} \Delta_{\rho} V_{t-1}+\alpha_{\rho} \beta_{\rho}^{\prime} \Delta_{1} V_{t-1}+\sum_{j=1}^{k-2} \Phi_{j} \Delta_{1} \Delta_{\rho} V_{t-j}+\epsilon_{t},
$$

and we calculate the updated largest characteristic root, $\hat{\rho}_{1}$. If this root is found to be strictly lager than unity we proceed through the subsequent steps of the estimation procedure. If the largest characteristic root is less than one, the system again reduces to a standard cointegrated $I(1)$ system. In any case, $\widehat{\beta}_{1}^{\prime}$ gives the estimated cointegrating vector between $P_{t}$ and $X_{t}$. 


\subsubsection{Non-explosiveness of rents}

Under the assumption of $H_{1}$ and $\rho_{1}>1$ we test the null hypothesis of non-explosive rents, that is imposing the restriction

$$
H_{X}: \quad \beta_{\rho}=(0,1)^{\prime} .
$$

This additional hypothesis restricts the model to

$$
M_{1 X}: \quad \Delta_{1} \Delta_{\rho} V_{t}=\mu_{v}+\alpha_{1} \beta_{1}^{\prime} \Delta_{\rho} V_{t-1}+\alpha_{\rho} \Delta_{1} X_{t-1}+\sum_{j=1}^{k-2} \Phi_{j} \Delta_{1} \Delta_{\rho} V_{t-j}+\epsilon_{t}
$$

The likelihood of this model is determined by a numerical profile argument. Specifically, we apply a grid search over a range of values for $\rho$. The likelihoods are then determined by reduced rank regressions of $\Delta_{1} \Delta_{\rho} V_{t}$ on $\Delta_{\rho} V_{t-1}$, where we correct for lagged rent growth, $\Delta_{1} X_{t-1}$, and differences, $\Delta_{1} \Delta_{\rho} V_{t-j}$. Maximizing the likelihood gives $\hat{\rho}_{1 X}$. The likelihood-ratio test of $H_{X}$ under the model $M_{1}$ is asymptotically $\chi^{2}(k-1)$, cf. Engsted and Nielsen (2012). If $H_{X}$ is rejected, $X_{t}$ cannot be taken to be non-explosive. The interpretation of an explosive root in the system as due to a rational bubble hinges on the non-rejection of $H_{X}$.

\subsubsection{The spread restriction}

Suppose that $H_{1}$ in (9) and $H_{X}$ in (11) are both not rejected. In this case we proceed by testing the restriction on the spread

$$
H_{S}: \quad \beta_{1}=(1,-1 / R)^{\prime}, \quad \text { where } \rho=1+R
$$

The restriction $\rho=1+R$ comes from equation (3) in Section 2. The restriction (13) implies that the model takes the form

$$
M_{1 X S}: \quad \Delta_{1} \Delta_{\rho} V_{t}=\mu_{v}+\alpha_{1} \Delta_{\rho} S_{t-1}+\alpha_{\rho} \Delta_{1} X_{t-1}+\sum_{j=1}^{k-2} \Phi_{j} \Delta_{1} \Delta_{\rho} V_{t-j}+\epsilon_{t}
$$

where the spread is inserted for $S_{t}=P_{t}-\frac{1}{\rho-1} X_{t}$. Maximization of the likelihood is done along the same numerical lines as in the previous step whereby we obtain $\hat{\rho}_{1 X S}$. The likelihood-ratio test statistic of $H_{S}$ in $M_{1 X}$ is asymptotically $\chi^{2}(1)$ and the simultaneous test of $H_{X}$ and $H_{S}$ in $M_{1}$ is asymptotically $\chi^{2}(k)$, cf. Engsted and Nielsen (2012). If $H_{S}$ is rejected, the procedure does not provide a unique estimate of the expected return, $R$, since the estimates provided by the explosive root $\widehat{\rho}_{1 X}$, and the cointegrating vector $\widehat{\beta}_{1}$, respectively, are statistically different. However, rejection of $H_{S}$ does not affect the conclusion that $P_{t}$ contains an explosive component. 


\subsection{Comparison with earlier bubble tests}

West (1987) developed an often cited specification test for rational stochastic bubbles. The test compares two sets of estimates of the underlying asset pricing model. The first set of estimates is consistent both with and without a bubble, while the second set is only consistent in the absence of a bubble. Equality of the two sets of estimates is then tested using a Hausman (1978) type specification test. The null hypothesis is no bubble, while the presence of a bubble should lead to rejection of the hypothesis. A problem with this procedure (noted by West himself in West, 1985) is that the test is not consistent. Under the alternative hypothesis that a bubble is present, the probability that the test will reject the null does not go to unity asymptotically. This is a direct consequence of the explosiveness of prices under the alternative. The Engsted and Nielsen (2012) procedure that we apply in this paper does not face this problem because in this procedure the null hypothesis explicitly involves a bubble.

Diba and Grossman (1988a) proposed to test for rational bubbles by using Bhargava's (1986) von Neumann-like statistic to test the null hypothesis of a unit root in prices against the explosive alternative. They also tested for cointegration between prices and fundamentals arguing that with a constant discount factor cointegration precludes bubbles while no cointegration would be consistent with the presence of a bubble. By using Bhargava's (1986) test for explosiveness the Diba and Grossman methodology assumes that the variables are at most a first-order autoregressive process, and the discount factor cannot be estimated but must be specified a priori. The Engsted and Nielsen (2012) procedure extends Diba and Grossman's procedure by specifying a general VAR for the variables that allows for an explosive root in addition to a possible common stochastic $I(1)$ trend (i.e. cointegration) between prices and fundamentals. In addition, the procedure allows estimation of the discount factor instead of prefixing it a priori as in the Diba-Grossman procedure.

Using a linear VAR for prices and fundamentals requires that the discount factor is constant. Most previous bubble studies in fact assume that the discount factor is constant. In the empirical finance literature this assumption is controversial since returns are often found to be predictable (see e.g. Cochrane, 2008). However, Engsted et al. (2012) show that a rational bubble may make returns appear predictable even when expected returns (and thereby the discount factor) is constant. In addition, even if expected returns are time-varying, Craine (1993) and Timmermann (1995) show that unless expected returns are highly persistent, the cointegrating relationship between prices and fundamentals implied by the constant discount factor present value model will hold approximately when the discount factor is time-varying. ${ }^{3}$

Evans (1991) showed in a simulation study that in a finite sample unit root and cointegration based tests will often not identify the explosive component of periodically collapsing rational

\footnotetext{
${ }^{3}$ Craine (1993) shows that with a time-varying (but stationary) discount factor the ratio between prices and fundamentals will be stationary under no bubbles. Thus, testing for explosiveness of this ratio is robust to the assumption about the discount factor. However, no other testable restrictions follow from Craine's approach.
} 
bubbles (see also Hall et al., 1999). Thus, the Engsted and Nielsen (2012) framework may not work well in that situation. By contrast, the Phillips et al. (2012) recursive procedure is explicitly designed to account for the periodically collapsing nature of the Evans type bubbles. However, the Phillips et al. (2012) procedure does not allow for estimation of the cointegrating relationship between prices and fundamentals because it does not allow both a unit root and an explosive root. If prices and fundamentals are cointegrated, i.e. have a common $I(1)$ trend, then, as we noted in Section 2, a solution would be to use instead of prices the ratio of prices to fundamentals. That eliminates the unit root. However, in contrast to the Engsted and Nielsen (2012) approach, the Phillips et al. (2012) methodology does not allow testing for a common $I(1)$ trend between prices and fundamentals. Furthermore, if prices have a unit root in addition to the explosive root, and this unit root is not shared with the unit root in fundamentals, the price-fundamental ratio will still contain both a unit root and an explosive root. It is not clear what the properties of the Phillips et al. procedure are in this case.

In fact, based on Diba and Grossman (1988a) many earlier empirical bubble studies have claimed that cointegration between prices and fundamentals rules out bubbles. For example, Phillips et al. (2011, p.206) state: "In the presence of bubbles, $p_{t}$ [price] is always explosive and hence cannot co-move or be cointegrated with $d_{t}$ [fundamental] if $d_{t}$ is itself not explosive. Therefore, an empirical finding of cointegration between $p_{t}$ and $d_{t}$ may be taken as evidence against the presence of bubbles." This statement is at best incomplete. As shown above the stochastic $I(1)$ trend in $d_{t}$ will be part of $p_{t}$ also in the presence of an explosive bubble, and the multivariate cointegrated VAR analysis based on reduced rank regressions will capture this feature. However, it is true that univariate regression based cointegration analysis will not be able to estimate the common $I(1)$ trend in $p_{t}$ and $d_{t}$ if $p_{t}$ also involves an explosive trend because the regression residuals will always be non-stationary in that case.

\section{Empirical results}

\subsection{The data}

We use official OECD data for 18 countries: ${ }^{4}$ Australia, Belgium, Canada, Switzerland, Germany, Denmark, Spain, Finland, France, the UK, Ireland, Italy, Japan, the Netherlands, Norway, New Zealand, Sweden, and the US. The dataset provided by the OECD contains quarterly observations from 1970Q1 to 2013Q4 for all countries, except Australia (begins 1972Q3), Belgium (begins 1976Q2), Spain (begins 1971Q1), Norway (begins 1979Q1), and Sweden (begins 1980Q1). The dataset contains seasonally adjusted real house prices and the price-rent ratio, which allows us to back out a real rent series for each country. The price indices and the price-rent ratios from the OECD are indexed with 2010 as base year. This indexation does not

\footnotetext{
${ }^{4}$ These data have been used in earlier analyses by OECD, e.g. Girouard et al. (2006).
} 
present a problem for the unit root tests for explosiveness of the price-rent ratio and most of the testable restrictions in the co-explosive VAR framework. The exception is the spread restriction (13), which requires that the level of rents is linked to prices such that we can calculate returns based on these two series. To facilitate this link we fix the price-rent ratios in 2013Q4 to the actual price-rent levels in 2013 reported by Numbeo. ${ }^{5}$ From the actual price-rent ratios and rent growth obtained from the backed out rent series, we obtain new rent series, which are directly linked to prices.

Our right-tailed unit root tests and date-stamping procedure will be based on the price-rent ratio. Figure 1 shows the (indexed) price-rent ratios. For most countries we observe a relatively stable ratio until the mid 1990s after which large increases in the ratio suggest that house prices started to decouple from rents. A group of countries (Denmark, Spain, Ireland, the Netherlands, and the US) has since the mid 2000s experienced noticeable decreases in the price-rent ratio caused by large drops in house prices, while for others (Australia, Belgium, Canada, Finland, France, the UK, Norway, New Zealand, and Sweden) the ratio has either stabilized or continued to increase. A few countries have experienced movements in the price-rent ratio different from this overall pattern. In Germany the ratio has generally been downward trending, while it has been relatively stable in Italy. Switzerland and Japan experienced large increases in house prices up to around 1990 after which prices fell dramatically in both countries. In recent years house prices have recovered somewhat in Switzerland, while prices continue to fall in Japan. Finland experienced price movements around 1990 similar to Switzerland and Japan, but since the mid 1990s prices have here generally been upward trending.

\subsection{Right-tailed unit root tests and date-stamping}

Table 1 shows the empirical results when performing the GSADF test on the price-rent ratio. In implementing the test we set the minimum window size $\left\lfloor T r_{0}\right\rfloor$ to 40 for each country and the lag length in the ADF regressions to 1 . To obtain critical values we perform 5,000 simulations for each sample size. According to the GSADF test the price-rent ratio has displayed explosive behavior in our sample period even at a $1 \%$ significance level in 15 of the 18 countries. In Norway the evidence of explosiveness in the price-rent ratio is less strong, but using a $10 \%$ significance level we still reject the null of a random walk against the explosive alternative. Only for two countries, Germany and Italy, we cannot reject the null hypothesis at any conventional significance level. The results from the GSADF test thus reveal evidence of bubbles in all of the 18 OECD countries' housing markets, except Germany and Italy.

In condensed form Figure 2 shows the results of the date-stamp procedure. The grey areas denote periods with explosiveness in the price-rent ratio as determined by the BSADF test. To be consistent with the GSADF test, we set the minimum window size to 40, the lag length in

\footnotetext{
${ }^{5} \mathrm{http}$ ///www.numbeo.com/property-investment/rankings_by_country.jsp.
} 
the $\mathrm{ADF}$ regressions to 1 , and perform 5,000 simulations at each point in time to obtain critical values. We exclude Germany and Italy from the date-stamping analysis since the GSADF test does not indicate explosiveness in these two countries' price-rent ratio. Abstracting from very short-lived explosive periods there appears to be a large degree of bubble synchronicity across the OECD countries. In the early 2000s we find evidence of explosiveness in 13 countries. For most of these countries the explosive behavior terminates around 2006 and 2007. For Belgium and Canada do we in 2013 still reject the null hypothesis of a random walk against the explosive alternative. The three countries for which there is no evidence of explosiveness in the price-rent ratio in the early 2000s are Japan, Finland, and Switzerland. Interestingly these countries all experience an explosive price-rent ratio around 1990. For Switzerland this is again the case in the last three years of our sample period.

\subsection{The co-explosive VAR analysis}

The main drawback of using univariate right-tailed unit root tests to detect bubbles, as in the previous section, is that the tests do not allow for both an explosive root and a unit root. Under the null hypothesis the time series process has a unit root, while under the alternative it has an explosive root. As mentioned in Section 2 if there is a bubble and prices and rents do not have a common $I(1)$ trend, i.e. they do not 'cointegrate', the price-rent ratio may contain both a unit root and an explosive root. This scenario is not a part of the hypotheses in the univariate test procedure. The conclusion that housing markets in most OECD countries have been subject to bubbles is thus based on the implicit assumption that prices and rents cointegrate. In this section we will use a co-explosive VAR framework to test for bubbles. This test procedure allows for both an explosive root and a unit root and thus accommodates the main drawback of the univariate right-tailed unit root tests. It does however have its own drawback in not allowing for bursting or partially bursting bubbles during the sample period. We address this issue by fixing the end of our sample period in the VAR analysis to the last occurence of explosive behavior in

the price-rent ratio as documented in Figure 2. We highlight these 'bubble collapses' in Figure 1.

Table 2 reports the results of the co-explosive VAR analysis for those countries where the univariate GSADF test in Table 1 indicates explosiveness in the price-rent ratio, i.e. all countries except Germany and Italy. The lag-length, $k$, in the VAR analyses is chosen to make the errors serially uncorrelated.

As seen, the unrestricted largest characteristic root, $\widehat{\rho}$, is larger than one for most of the countries, in accordance with the univariate analysis. However, for Belgium, the Netherlands, and New Zealand, $\widehat{\rho}<1$ which indicates no explosiveness in these three countries. For Belgium and Netherlands the cointegration test for a rank of $r=0$ rejects while $r=1$ cannot be rejected at a $5 \%$ level, and the implied values for the expected quarterly real housing return from the 
estimated cointegrating vectors are $\widehat{R}=1 / 188.69=0.0053(0.53 \%)$ and $\widehat{R}=1 / 32.59=0.0307$ $(3.07 \%)$, respectively, for Belgium and the Netherlands. For New Zealand the rank test does not indicate cointegration between prices and rents.

In four of the countries (Australia, Denmark, Finland, and France) the estimated VAR system has an explosive root and there is no evidence of cointegration between prices and rents. This suggest the presence of an explosive housing bubble in these countries and that prices have no low-frequency relation to fundamentals measured by rents.

For another group of countries (Canada, Spain, the UK, and also Switzerland and Japan for the early part of the sample) there is evidence of a common $I(1)$ trend, i.e. cointegration, between prices and rents with estimated expected quarterly real returns ranging from $0.19 \%$ (Canada) to $3.88 \%$ (the UK). However, in these cases the explosive root disappears when imposing a cointegrating rank of $r=1$. Thus, either the $\widehat{\rho}$ estimates in Table 2 are indistinguishable from one (such that the VAR is a standard cointegrated $I(1)$ system) or there is a common explosive root between rents and prices in these five countries. A possible explanation for this result is a constant long-run growth rate in rents which will show up as an exponential increase in the level of rents and thereby imply an explosive root in the VAR system.

For the remaining four countries (Ireland, Norway, Sweden, and the US) there is evidence of both a common $I(1)$ trend between prices and rents and an explosive root. As seen from Table 2, the largest characteristic root remains larger than one when imposing a cointegrating rank of $r=1\left(\widehat{\rho}_{1}>1\right)$. For Ireland, Norway and Sweden, the $H_{X}$ hypothesis, $\beta_{\rho}=(0,1)^{\prime}$, is not rejected at a $5 \%$ level implying no explosive rents. Thus, for these three countries there is evidence of an explosive bubble in house prices but also that there is a low-frequency relation between prices and rents. For the US, however, the hypothesis of non-explosive rents is statistically rejected. This result contrasts with the results by Kivedal (2013) who on US data - and also using the Engsted and Nielsen (2012) approach - does not reject the hypothesis of non-explosive rents. In all four countries the largest characteristic root remains larger than one when imposing the spread restriction, $H_{S}: \beta_{1}=(1,-1 / R)$ with $\rho=1+R,\left(\widehat{\rho}_{1 \mathrm{X}}>1 ; \widehat{\rho}_{1 \mathrm{XS}}>1\right)$. However, the restriction is statistically rejected in all four cases. As seen from the estimated $\beta_{1}^{\prime}$ vector, the expected quarterly real housing return, $R$, is negative which contrasts with the estimate of $R$ from the explosive root which gives $\widehat{R}$ values ranging from $0.1 \%$ (the US) to $4.5 \%$ (Norway). These large differences in the estimates of $R$ from the cointegrating vector $\beta_{1}^{\prime}$ on the one hand and the explosive root, $\rho$, on the other hand probably explain why we reject the spread restriction.

The analysis in this section has documented some interesting cross-country differences in the dynamics of house prices and rents in the OECD area, and also some important differences to the analysis in Section 4.2. For four of the countries the VAR results are consistent with the univariate analysis on the price-rent ratio in that we find both a common $I(1)$ trend between prices and rents and an explosive root. However, for the remaining 12 countries the VAR 
results are qualitatively different from the univariate results. In particular, in several cases the explosive root is eliminated when imposing the cointegration restriction between prices and rents. Also, in a number of cases there is an explosive root but no common $I(1)$ trend, which in theory invalidates the GSADF test procedure applied to the price-rent ratio, since this ratio contains a unit root in addition to an explosive root.

In general, for 8 of the 18 countries in our sample, the results in this section lend support to the common claim that a housing bubble has been a main driver of house prices throughout the OECD area, while for the remaining 10 countries the co-explosive VAR analysis does not indicate the presence of an explosive housing bubble.

\section{Concluding remarks}

In this paper we investigate the empirical relation between house prices and rents in light of detecting and assessing explosive behaviour.

First, we use the univariate right-tailed unit root test procedure of Phillips et al. (2012) on the price-rent ratio in order to identify and date-stamp periods with explosive behaviour. For all but two of the 18 OECD countries (Germany and Italy) we find evidence of explosiveness. In date-stamping the bubble periods we detect a large degree of bubble synchronicity in the early 2000s and to a certain degree also around 1990. The explosive alternative of the univariate test procedure implicitly assumes cointegration of prices and rents.

To allow for both an explosive root and a unit root we also test for bubbles using the co-explosive VAR framework of Engsted and Nielsen (2012). From this analysis we find that there are large differences in the dynamics of housing markets across countries. We find four countries for which the two approaches are mutually consistent in the sense that we find a common stochastic trend between prices and rents along with an explosive root. In all other cases we find either no explosive behaviour, that rent-related fundamentals are not the relevant drivers of house prices, or that there is a common explosive root between prices and rents, which is indistinguishable from the common $I(1)$ trend. 


\section{References}

[1] Bhargava, A. (1986). On the theory of testing for unit roots in observed time series. Review of Economic Studies 53, 369-384.

[2] Brunnermeier, M.K. and Julliard, C. (2008). Money illusion and housing frenzies. Review of Financial Studies 21, 135-180.

[3] Campbell, D., Morris, D., Gallin, J., and Martin, R. (2009). What moves housing markets: A variance decomposition of the rent-price ratio. Journal of Urban Economics 66, 90-102.

[4] Campbell, J.Y. and Shiller, R.J. (1987). Cointegration and test of present value models. Journal of Political Economy 95, 1062-1088.

[5] Case, K.E. and Shiller, R.J. (1989). The efficiency of the market for single-family homes. American Economic Review 79, 125-137.

[6] Cochrane, J.H. (2008). The dog that did not bark. A defense of return predictability. Review of Financial Studies 21, 1533-1575.

[7] Cochrane, J.H. (2011). Discount rates (Presidential address). Journal of Finance

[8] Craine, R. (1993). Rational bubbles: A test. Journal of Economic Dynamics and Control $17,829-846$.

[9] Diba, B.T. and Grossman, H.I. (1988a). Explosive rational bubbles in stock prices? American Economic Review 78, 520-530.

[10] Diba, B.T. and Grossman, H.I. (1988b). The theory of rational bubbles in stock prices. Economic Journal 98, 746-757.

[11] Engsted, T. (2006). Explosive bubbles in the cointegrated VAR model. Finance Research Letters 3, 154-162.

[12] Engsted, T. and Nielsen, B. (2012). Testing for rational bubbles in a coexplosive vector autoregression. Econometrics Journal 15, 226-254.

[13] Engsted, T. and Pedersen, T.Q. (2013). Predicting returns and rent growth in the housing market using the rent-to-price ratio: Evidence from the OECD countries. CREATES Working Paper, Aarhus University.

[14] Engsted, T. and Pedersen, T.Q. (2014). Housing market volatility in the OECD area: Evidence from VAR based return decompositions. Journal of Macroeconomics 42, 91-103.

[15] Engsted, T., Pedersen, T.Q., and Tanggaard, C. (2012). The log-linear return approximation, bubbles, and predictability. Journal of Financial and Quantitative Analysis 47, 643-665. 
[16] Evans, G.W. (1991). Pitfalls in testing for explosive bubbles in asset prices. American Economic Review 81, 922-930.

[17] Gallin, J. (2008). The long-run relationship between house prices and rents. Real Estate Economics 36, 635-658.

[18] Gelain, P. and Lansing, K.L. (2014). House prices, expectations, and time-varying fundamentals. Journal of Empirical Finance 29, 3-25.

[19] Ghysels, E., Plazzi, A., Torous, W., and Valkanov, R. (2013). Forecasting real estate prices. In: Elliott, G. and A. Timmermann (Eds.), Handbook of Economic Forecasting 2, 509-580.

[20] Girouard, N., Kennedy, M., van den Noord, P., André, C., 2006. Recent house price developments: The role of fundamentals. OECD Economics Department Working Paper no. 475 .

[21] Hall, S.G., Psaradakis, Z. and Sola, M. (1999). Detecting periodically collapsing bubbles: A Markov-switching unit root test. Journal of Applied Econometrics 14, 143-154.

[22] Hamilton, B.W. and Schwab, R.M. (1985). Expected appreciation in urban housing markets. Journal of Urban Economics 18, 103-118.

[23] Hausman, J.A. (1978). Specification tests in econometrics. Econometrica 46, 1251-1271.

[24] Himmelberg, C., Mayer, C., and Sinai, T. (2005). Assessing high house prices: Bubbles, fundamentals and misperceptions. Journal of Economic Perspectives 19, 67-92.

[25] Johansen, S. (1995). Likelihood-Based Inference in Cointegrated Vactor Autoregressive Models. Oxford University Press.

[26] Kivedal, B.K. (2013). Testing for rational bubbles in the US housing market. Journal of Macroeconomics 38, 369-381.

[27] Krainer, J. and Wei, C. (2004). House prices and fundamental value. FRBSF Economic Letter, November-October 2004, 1-3.

[28] McCarthy, J. and Peach, R.W. (2004). Are home prices the next "bubble"? FRBNY Economic Policy Review, December 2004, 1-17.

[29] Meese, R. and Wallace, N. (1994). Testing the present value relation for housing prices: Should I leave my house in San Francisco? Journal of Urban Economics 35, 245-266.

[30] Nielsen, B. (2010). Analysis of coexplosive processes. Econometric Theory 26, 882-915.

[31] Phillips, P.C.B., Shi, S.-P., and Yu, J. (2012). Testing for multiple bubbles. Cowles Foundation discussion paper no. 1843. 
[32] Phillips, P.C.B. and Yu, J. (2011). Dating the timeline of financial bubbles during the subprime crisis. Quantitative Economics 2, 455-491.

[33] Phillips, P.C.B., Wu, Y. and Yu, J. (2011). Explosive behavior in the 1990s NASDAQ: When did exuberance escalate asset values? International Economic Review 52, 201-226.

[34] Plazzi, A., Torous, W., and Valkanov, R. (2010). Expected returns and expected growth in rents of commercial real estate. Review of Financial Studies 23, 3469-3519.

[35] Shiller, R.J. (2005). Irrational Exuberance (2nd edition). Princeton University Press, Princeton and Oxford.

[36] Timmermann, A. (1995). Cointegration tests of present value models with a time-varying discount factor. Journal of Applied Econometrics 10, 17-31.

[37] West, K.D. (1985). A specification test for speculative bubbles. Working Paper, Princeton University.

[38] West, K.D. (1987). A specification test for speculative bubbles. Quarterly Journal of Economics 102, 553-580. 


\section{A Data}
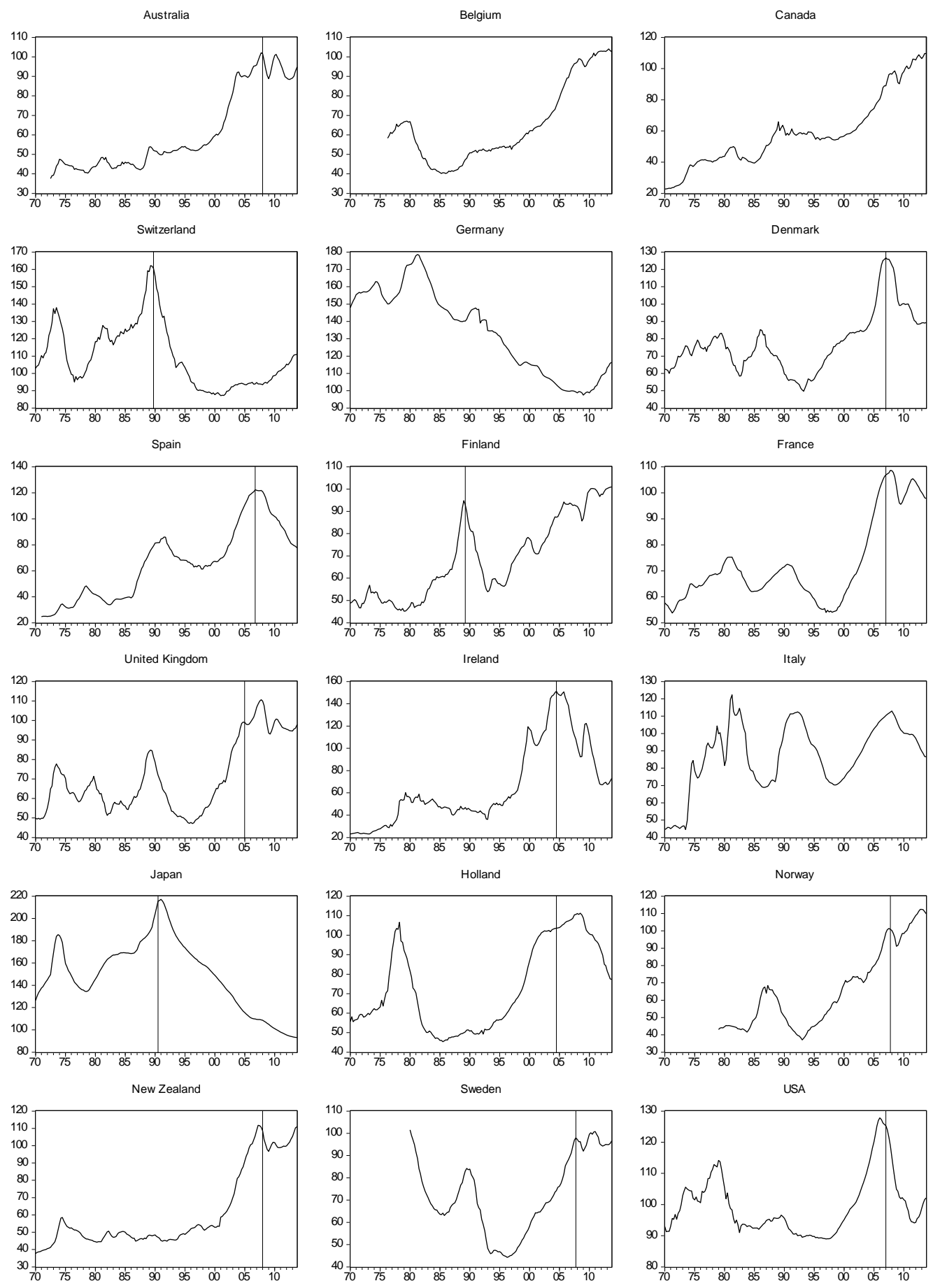

Note: The vertical lines indicate the end of a bubble period identified using the BSADF test with minimum window size of 40 observations, lag length of 1 in the auxiliary regressions, and finite-sample critical values obtained using 5000 simulations.

Figure 1: Price-rent ratio for the 18 OECD countries. 


\section{B Empirical findings}

Table 1: Right-tailed unit root tests on the price-rent ratio.

\begin{tabular}{l|c|c|ccc} 
Country & $\mathrm{T}$ & GSADF & $90 \%$ & $95 \%$ & $99 \%$ \\
\hline \hline Australia & 166 & 5.545 & 1.515 & 1.7860 & 2.3364 \\
Belgium & 151 & 7.279 & 1.438 & 1.7208 & 2.2651 \\
Canada & 176 & 4.944 & 1.545 & 1.8199 & 2.3261 \\
Switzerland & 176 & 3.572 & 1.545 & 1.8199 & 2.3261 \\
Germany & 176 & 1.160 & 1.545 & 1.8199 & 2.3261 \\
Denmark & 176 & 2.558 & 1.545 & 1.8199 & 2.3261 \\
Spain & 172 & 2.915 & 1.537 & 1.8225 & 2.3089 \\
Finland & 176 & 3.782 & 1.545 & 1.8199 & 2.3261 \\
France & 176 & 4.103 & 1.545 & 1.8199 & 2.3261 \\
United Kingdom & 176 & 2.670 & 1.545 & 1.8199 & 2.3261 \\
Ireland & 176 & 4.658 & 1.545 & 1.8199 & 2.3261 \\
Italy & 176 & 0.260 & 1.545 & 1.8199 & 2.3261 \\
Japan & 176 & 2.412 & 1.545 & 1.8199 & 2.3261 \\
Netherlands & 176 & 6.666 & 1.545 & 1.8199 & 2.3261 \\
Norway & 140 & 1.646 & 1.404 & 1.6910 & 2.2191 \\
New Zealand & 176 & 4.388 & 1.545 & 1.8199 & 2.3261 \\
Sweden & 136 & 2.818 & 1.396 & 1.6650 & 2.2097 \\
United States & 176 & 5.580 & 1.545 & 1.8199 & 2.3261 \\
\hline \hline
\end{tabular}

Note: In calulating the GSADF test we set the minimum window size to 40 observations and the lag length to 1 in the auxiliary regressions. CV denotes the finite-sample critical values based on 5000 simulations. 


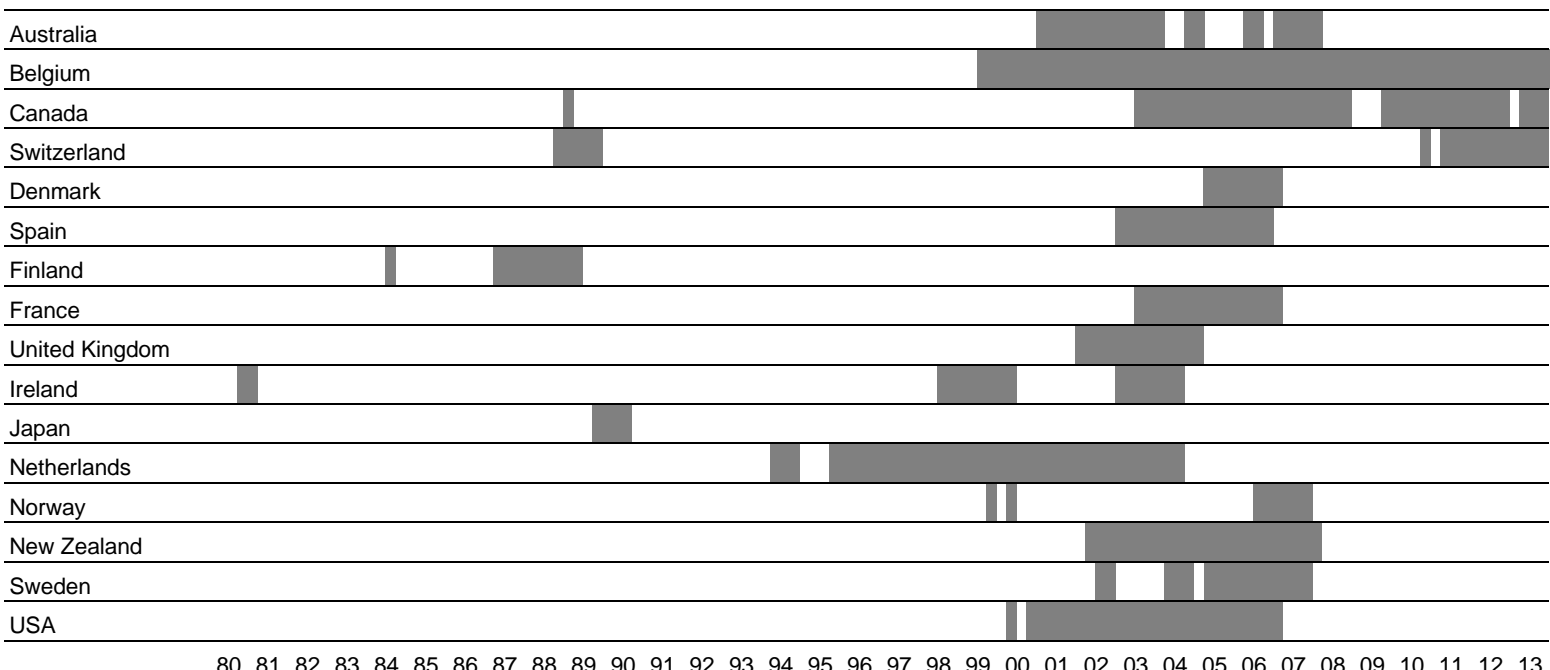

Note: Explosiveness is identified using the BSADF test with a minimum window size to 40 observations, a lag length to 1 in the auxiliary regressions, and finite-sample critical values based on 5000 simulations.

Figure 2: Date-stamping explosiveness in the price-rent ratio. 


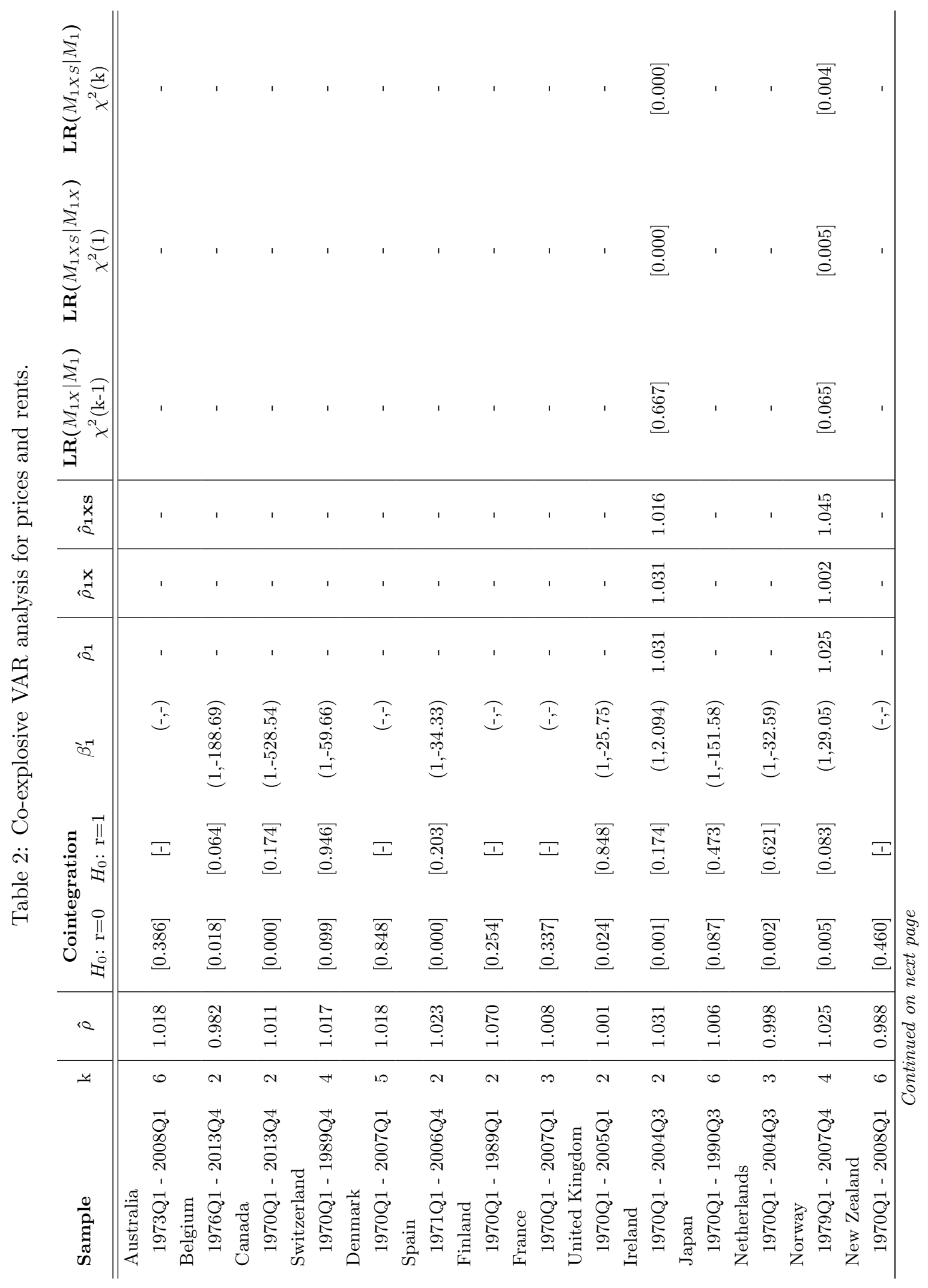




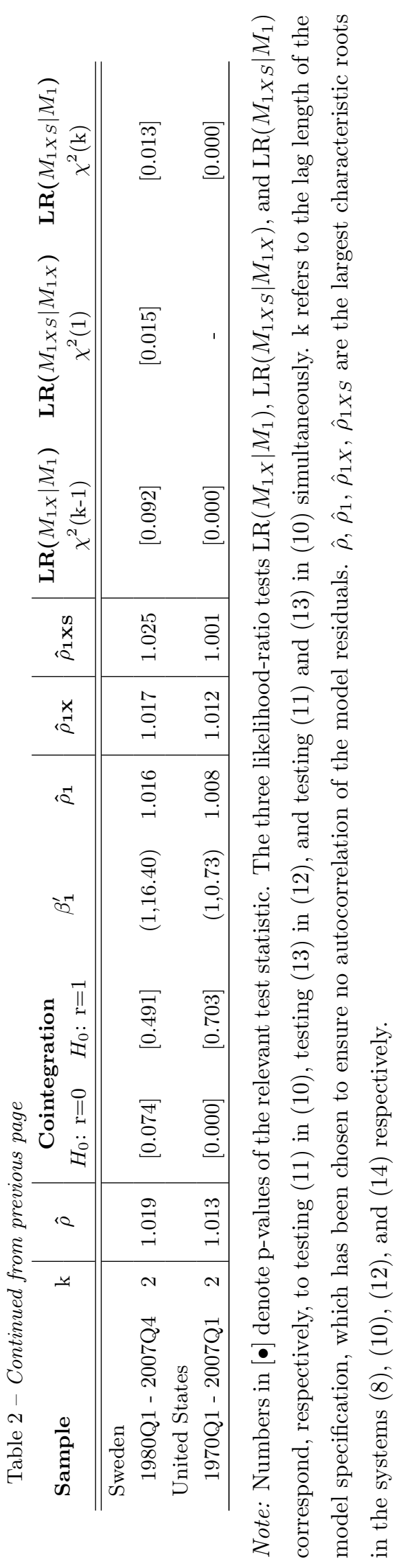


2014-42: $\quad$ Laurent A. F. Callot, Anders B. Kock and Marcelo C. Medeiros: Estimation and Forecasting of Large Realized Covariance Matrices and Portfolio Choice

2014-43: $\quad$ Paolo Santucci de Magistris and Federico Carlini: On the identification of fractionally cointegrated VAR models with the $F(d)$ condition

2014-44: $\quad$ Laurent Callot, Niels Haldrup and Malene Kallestrup Lamb: Deterministic and stochastic trends in the Lee-Carter mortality model

2014-45: $\quad$ Nektarios Aslanidis, Charlotte Christiansen, Neophytos Lambertides and Christos S. Savva: Idiosyncratic Volatility Puzzle: Influuence of Macro-Finance Factors

2014-46: $\quad$ Alessandro Giovannelli and Tommaso Proietti: On the Selection of Common Factors for Macroeconomic Forecasting

2014-47: $\quad$ Martin M. Andreasen and Andrew Meldrum: Dynamic term structure models: The best way to enforce the zero lower bound

2014-48: $\quad$ Tim Bollerslev, Sophia Zhengzi Li and Viktor Todorov: Roughing up Beta: Continuous vs. Discontinuous Betas, and the Cross-Section of Expected Stock Returns

2914-49: Tim Bollerslev, Viktor Todorov and Lai Xu: Tail Risk Premia and Return Predictability

2014-50: Kerstin Gärtner and Mark Podolskij: On non-standard limits of Brownian semistationary

2014-51: Mark Podolskij : Ambit fields: survey and new challenges

2014-52: Tobias Fissler and Mark Podolskij: Testing the maximal rank of the volatility process for continuous diffusions observed with noise

2014-53: Cristina M. Scherrer: Cross listing: price discovery dynamics and exchange rate effects

2014-54: Claudio Heinrich and Mark Podolskij: On spectral distribution of high dimensional covariation matrices

2014-55: Gustavo Fruet Dias and Fotis Papailias: Forecasting Long Memory Series Subject to Structural Change: A Two-Stage Approach

2014-56: Torben G. Andersen, Nicola Fusari and Viktor Todorov: The Risk Premia Embedded in Index Options

2014-57: $\quad$ Eduardo Rossi and Paolo Santucci de Magistris: Indirect inference with time series observed with error

2014-58: $\quad$ Anders Bredahl Kock and Haihan Tang: Inference in High-dimensional Dynamic Panel Data Models

2015-01 Tom Engsted, Simon J. Hviid and Thomas Q. Pedersen: Explosive bubbles in house prices? Evidence from the OECD countries 